\title{
Simultaneous development of COVID-19 pneumonia and pulmonary metastasis in a known case of chondrosarcoma: a case report
}

\author{
Afshin Rakhsha', Zahra Mahboubi-Fooladi ${ }^{2}$ and Anya Jafari ${ }^{*}$
}

\begin{abstract}
Background: The outbreak of coronavirus disease 2019 (COVID-19) started in December 2020, and is a global problem now. There are several sets of established data regarding computed tomography (CT) findings in COVID-19 pneumonia with many differential diagnoses. During the early days of the pandemic, there was little data regarding lung CT features of COVID-19 in a cancer patient. In this paper, we described a rare case of simultaneous presentation of COVID-19 with pulmonary metastasis.
\end{abstract}

Case presentation: A Persian patient with a history of chondrosarcoma presented to our clinic during the COVID19 pandemic with a new-onset cough. He had experienced no recurrence during previous follow-up visits. Chest CT scan revealed numerous bilateral small peripheral and perilymphatic pulmonary nodules, unilateral ground-glass patch, and nodular interlobular septal thickening. Biopsy of the pulmonary nodules established pulmonary metastasis of chondrosarcoma origin, and pharyngeal reverse transcription polymerase chain reaction (RT-PCR) was positive for COVID-19.

Conclusion: Pulmonary metastasis should be considered as a differential diagnosis of COVID-19 features in cancer patients in the pandemic era.

Keywords: Case report, COVID-19, SARS-CoV-2, Chondrosarcoma, Pulmonary metastasis

\section{Background}

Coronavirus disease 2019 (COVID-19), caused by the novel severe acute respiratory syndrome coronavirus 2 (SARS-CoV-2), first appeared in Wuhan, China, characterized by acute mild to severe respiratory symptoms. Immunocompromised patients are at high risk of COVID-19 infection. Differentiating COVID-19 lung features from lung involvement by metastasis is especially

\footnotetext{
*Correspondence: anyajafari@yahoo.com

${ }^{1}$ Department of Radiation Oncology, Shahid Beheshti University

of Medical Sciences, Shohada-e Tajrish Hospital, Shahrdari St, 1989934148 Tehran, Iran

Full list of author information is available at the end of the article
}

challenging for oncologists during the pandemic. Here we present a known case of sarcoma with challenging chest $\mathrm{CT}$ scan findings.

\section{Case presentation}

A 54-year-old Iranian man, with a history of chondrosarcoma of the left lower limb, presented to our clinic with a chief complaint of cough in March 2020 during the outbreak of COVID-19. The patient had presented with a 6 $\mathrm{cm}$ mass in the left anterior thigh 3 years earlier, and at that time, after an incisional biopsy, he underwent wide local excision of the primary tumor. Pathology examination revealed extraskeletal myxoid chondrosarcoma with moderate differentiation, so he received postoperative original author(s) and the source, provide a link to the Creative Commons licence, and indicate if changes were made. The images or other third party material in this article are included in the article's Creative Commons licence, unless indicated otherwise in a credit line to the material. If material is not included in the article's Creative Commons licence and your intended use is not permitted by statutory regulation or exceeds the permitted use, you will need to obtain permission directly from the copyright holder. To view a copy of this licence, visit http://creativecommons.org/licenses/by/4.0/. The Creative Commons Public Domain Dedication waiver (http://creativeco mmons.org/publicdomain/zero/1.0/) applies to the data made available in this article, unless otherwise stated in a credit line to the data. 
radiotherapy, and as there was no evidence of recurrence, was followed up every 3 months until the outbreak. Familial history and other medical history were unremarkable.

He complained of progressive dry cough and sweating. No history of fever, weight loss, or any other symptoms was reported. Examination of vital signs revealed a respiratory rate of 20 breaths/minute, blood pressure of $100 / 60 \mathrm{mmHg}$, oral temperature of $36.9{ }^{\circ} \mathrm{C}$, and pulse rate of 120 beats/minute. On lung auscultation, he had bilateral fine rales. Blood tests revealed leukopenia (3.2 $\times 10^{9} / \mathrm{L}$, normal: $\left.4-9 \times 10^{9} / \mathrm{L}\right)$ and lymphopenia $(1.2 \times$ $\left.10^{9} / \mathrm{L}\right)$.

Based on two main differential diagnoses of pulmonary metastasis or SARS-CoV-2 infection, he underwent a chest computed tomography (CT) scan with intravenous contrast and SARS-CoV-2 reverse transcription polymerase chain reaction (RT-PCR).

The SARS-CoV-2 RT-PCR test result, based on a pharyngeal swap sample, was positive. Chest CT revealed numerous bilateral small peripheral and perilymphatic pulmonary nodules, unilateral ground-glass patch, and nodular interlobular septal thickening. There was no evidence of mediastinal lymphadenopathy or pleural effusion (Fig. 1).

Due to the challenging CT findings, it was difficult to rule out pulmonary metastasis in this case, so several lung biopsies were taken, and the pathology report revealed a recurrence of myxoid sarcoma in the lung. The patient was cared for as a COVID-19-infected case, and subsequently palliative chemotherapy was administered.

\section{Discussion}

Since SARS-CoV-2 infection was initially reported in China in January 2020, several clinical manifestations have been documented [1]. The most common presentations are fever (88.7\%), dry cough (57.6\%), and dyspnea [2]. It is expected that immunocompromised patients are at increased risk of infection in comparison with the general population [3, 4]. Despite reports about SARS-CoV-2 infection in cancer patients, it is not known whether the infection presents differently from that in the normal population [5], and the same is true about the CT features. In our case, the last cancer treatment was localized radiotherapy 3 years earlier, and the patient was monitored as cancer-free before the pandemic, so it was reasonable to consider COVID19 infection as the differential diagnosis of dry cough in this patient.

COVID-19 pneumonia can have a wide spectrum of CT findings including ground-glass opacity (GGO) and rarely, discrete pulmonary nodules, as in our patient [6]. There are many publications on this issue, and some rare radiologic presentations have been described. The most common lung features of COVID-19 pneumonia are bilateral and multi-lobe involvement with subpleural GGO \pm consolidations [7]. On the other hand, metastatic chondrosarcoma of bone can show bilateral lobulated nodules with a bilateral diffuse distribution pattern and internal calcification [8]. Unilateral one-lobe involvement with GGO is mostly in favor of cancer [9]. It is not clear whether the pulmonary involvement of COVID-19 in cancer patients is different from that in the general population. Therefore, the development of new pulmonary nodules in a patient with a history of malignancy during the pandemic raises the need to evaluate each of these diagnoses.

Due to our challenge in the differentiation of these two entities on CT scan, nonspecific clinical symptoms, and reported false-positive COVID-19 RT-PCR results, we decided to perform lung biopsy, which established the metastasis. The patient received azithromycin and
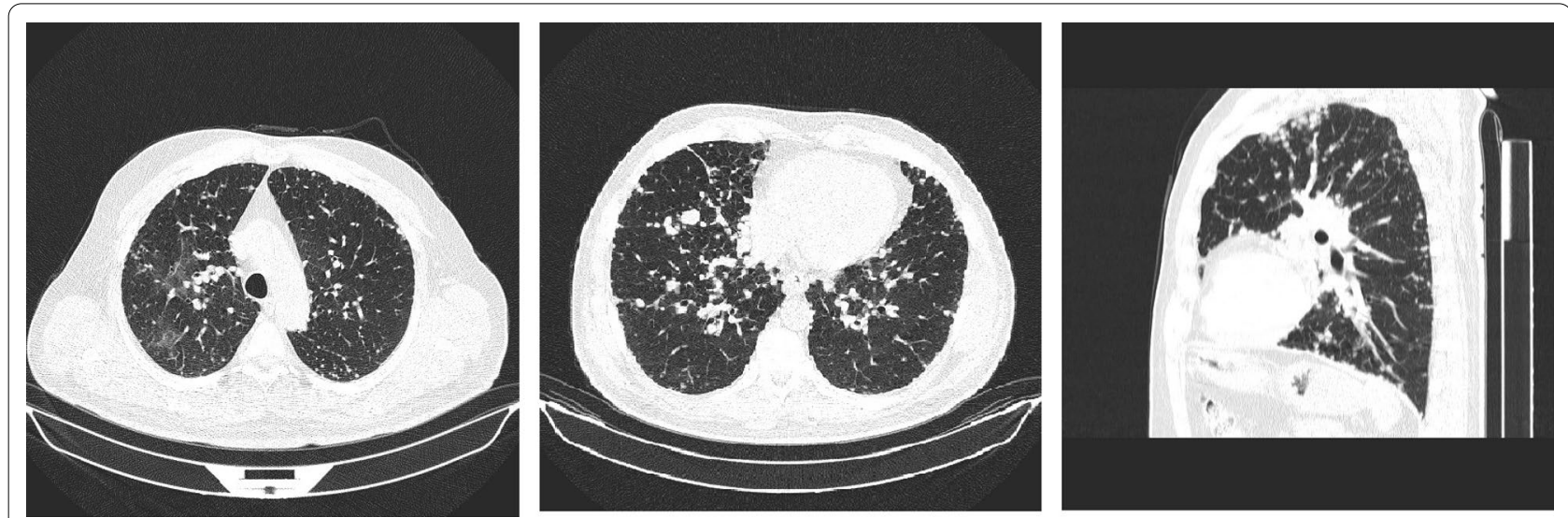

Fig. 1 Axial and sagittal views of chest CT scan of a patient with COVID-19 and pulmonary metastasis show nodules and grand glass opacities 
tocilizumab for COVID-19 infection, and after recovery, palliative chemotherapy was planned.

\section{Conclusion}

Although cancer patients are more likely to be infected with COVID-19, pulmonary metastasis should be kept in mind as a differential diagnosis of COVID-19 lung features, especially with pulmonary nodules in these patients during the pandemic.

\section{Abbreviations}

COVID-19: Coronavirus disease 2019; CT scan: Computed tomography scan; RT-PCR: Reverse transcription polymerase chain reaction; GGO: Ground-glass opacity.

\section{Acknowledgements}

Not applicable.

\section{Authors' contributions}

AJ and AR conceived the idea and study design. AJ gathered the data and wrote a primary manuscript draft. ZMF reported the CT scans. All authors read and approved the final manuscript

\section{Funding}

This research did not receive any specific grant from funding agencies in the public, commercial, or not-for-profit sectors.

\section{Availability of data and materials}

Data sharing is not applicable to this article, as no data sets were generated or analyzed during the current study.

\section{Ethics approval and consent to participate}

Not applicable.

\section{Consent for publication}

Written informed consent was obtained from the patient for publication of this case report and any accompanying images. A copy of the written consent is available for review by the Editor-in-Chief of this journal.

\section{Competing interests}

The authors declare that they have no competing interests.

\section{Author details}

1 Department of Radiation Oncology, Shahid Beheshti University of Medical Sciences, Shohada-e Tajrish Hospital, Shahrdari St, 1989934148 Tehran, Iran.
${ }^{2}$ Department of Radiology, Shahid Beheshti University of Medical Sciences, Tehran, Iran.

Received: 15 August 2020 Accepted: 22 February 2021

Published online: 28 April 2021

\section{References}

1. Jiang F, Deng L, Zhang L, Cai Y, Cheung CW, Xia Z. Review of the clinical characteristics of coronavirus disease 2019 (COVID-19). J Gen Intern Med. 2020;35(5):1545-9.

2. Rodriguez-Morales AJ, Cardona-Ospina JA, Gutiérrez-Ocampo E, Villamizar-Peña R, Holguin-Rivera Y, Escalera-Antezana JP, et al. Clinical, laboratory and imaging features of COVID-19: a systematic review and meta-analysis. Travel Med Infect Dis. 2020;34:101623.

3. Wang H, Zhang L. Risk of COVID-19 for patients with cancer. Lancet Oncol. 2020;21(4):e181.

4. Motlagh A, Yamrali M, Azghandi S, Azadeh P, Vaezi M, Ashrafi F, et al. COVID19 prevention and care; a cancer specific guideline. Arch Iran Med. 2020;23(4):255-64.

5. Zhang L, Zhu F, Xie L, Wang C, Wang J, Chen R, et al. Clinical characteristics of COVID-19-infected cancer patients: a retrospective case study in three hospitals within Wuhan, China. Ann Oncol. 2020;31(7):894-901.

6. Khazaei M, Mahdavi A, Mahboubi-Fooladi Z, Moharamzad Y, Asgari R, Zarei E, et al. Chest CT imaging spectrum of coronavirus disease 2019 (COVID-19) pneumonia: a pictorial essay. Iran J Radiol. 2019. https://doi. org/10.5812/iranjradiol.103166.

7. Ye Z, Zhang Y, Wang Y, Huang Z, Song B. Chest CT manifestations of new coronavirus disease 2019 (COVID-19): a pictorial review. Eur Radiol. 2020;30(8):4381-9.

8. McLoughlin E, Davies A, Iqbal A, James S, Botchu R. The diagnostic significance of pulmonary nodules on CT thorax in chondrosarcoma of bone. Clin Radiol. 2020;75(5):395.e7-e16.

9. Meng H, Xiong R, He R, Lin W, Hao B, Zhang L, et al. Comparison of chest CT images featured with ground grass opacity between COVID-19 pneumonia and early-stage lung cancer in Wuhan, China: a single-centered, retrospective, observational study. SSRN J. 2020. https://doi.org/10.2139/ ssrn.3551427.

\section{Publisher's Note}

Springer Nature remains neutral with regard to jurisdictional claims in published maps and institutional affiliations.

\footnotetext{
Ready to submit your research? Choose BMC and benefit from:

- fast, convenient online submission

- thorough peer review by experienced researchers in your field

- rapid publication on acceptance

- support for research data, including large and complex data types

- gold Open Access which fosters wider collaboration and increased citations

- maximum visibility for your research: over $100 \mathrm{M}$ website views per year
}

At BMC, research is always in progress.

Learn more biomedcentral.com/submissions 